\title{
Comparison of sympathectomy and cilostazol treatment results in non-revascularized critical leg ischemia
}

\author{
๑DYlldırım Gültekin ${ }^{1}$, @Ali Bolat ${ }^{1}$, $\odot$ Hüseyin Gemalmaz ${ }^{2}$ \\ ${ }^{1}$ Kırıkkale University, Faculty of Medicine, Department of Cardiovascular Surgery, Kırıkkale, Turkey \\ ${ }^{2}$ Prof. Dr. Cemil Taşçığlu City Hospital, Clinic of Cardiovascular Surgery, İstanbul, Turkey
}

Cite this article as: Gültekin Y, Bolat A, Gemalmaz H. Comparison of sympathectomy and cilostazol treatment results in non-revascularized critical leg ischemia. J Health Sci Med 2021; 4(3): 366-371.

\begin{abstract}
Objective: The aim of this retrospective study is to compare the efficacy of sympathectomy and cilostazol therapy in critical limb ischemia that cannot be revascularized.

Material and Method: This study was retrospectively conducted on 30 patients who underwent lumbar sympathectomy (Group 1) and received cilotazol treatment (Group 2) between January 2017 and August 2020. Demographic data, comorbidity, complications, wound healing, walking distance and pain scale records of the patients were determined by examining the hospital registry system and statistical analysis was performed.

Results: In the study, no significant difference was found between the two groups in terms of walking distance and ischemic pain in the statistical analysis of the data before treatment, at the $3^{\text {rd }}, 6^{\text {th }}, 12^{\text {th }}$ and $24^{\text {th }}$ months $(p>0.05)$. However, a statistically significant difference was found between the pre-treatment data and the data at the $3^{\text {rd }}, 6^{\text {th }}, 12^{\text {th }}$ and $24^{\text {th }}$ months in both Group 1 and Group 2 in terms of walking distance and ischemic pain $(\mathrm{p}<0.001)$. In the time periods followed in both groups, it was observed that there was an increase in walking distance and a decrease in ischemic pain.

Conclusion: Cilostazol treatment may be preferred as a good alternative treatment method compared to lumbar sympathectomy in critical leg ischemia.
\end{abstract}

Keywords: Critical leg ischemia, sympathectomy, cilostazol

\section{INTRODUCTION}

Peripheral artery disease (PAH) is a chronic and progressive deterioration of the limb arterial blood circulation due to systemic atherosclerosis and inflammation. It usually occurs as a result of systemic atherosclerosis. Because it covers a wide age group and has a high morbidity, it poses a major problem in terms of public health (1). The prevalence of peripheral artery disease is reported to be $17 \%$ in women over the age of 65 and $20 \%$ in men (2). Its incidence increases with age (3). Risk factors such as increased total cholesterol levels, increased frequency of metabolic syndrome, obesity and widespread smoking, diabetes, and hypertension can lead to cardiovascular diseases (4).

Peripheral artery disease usually appears as a claudication intermittent. The shortened walking distance due to ischemic pain over time indicates that the disease progresses. Rest pain, coldness in the extremity, pallor, dystrophic changes, ischemic leg ulcers, foot wounds, and in very advanced cases, cyanosis and necrosis may be encountered $(5,6)$.
In the treatment of peripheral artery disease, medical treatment of atherosclerotic risk factors such as hypertension, hyperlipidemia, and diabetes, as well as lifestyle changes such as weight loss, exercise, and smoking cessation, are required. In the absence of proper care, patients with $\mathrm{PAH}$ have ischemia leading to amputation and increasing morbidity and mortality (7). It is often necessary to eliminate ischemia by surgical revascularization or endovascular angioplasty. Critical leg ischemia constitutes the class 3-4 patient group according to the fontaine classification, which cannot be revascularized. Walking distance is very short. Even at rest, there may be pain in the extremities (8). Lumbar sympathectomy is one of the surgical methods applied in addition to medical treatment in patients with critical leg ischemia that cannot be revascularized (9). Lumbar sympathectomy is one of the important treatment approaches that can be chosen in occlusive artery diseases, when the patients are well selected and away 
from tobacco habit (10). Current application forms have a wide range of open surgical techniques, endoscopic and chemical methods (11). The purpose of sympathectomic denervation is to increase regional blood flow by removing vasomotor tone in the extremity. The early effect of sympathectomy is that it significantly reduces the peripheral resistance of skin arterioles (12). After lumbar sympathectomy in the lower extremity, $25 \%$ and $50 \%$ increases in blood flow were detected (13).

Cilostazol is a phosphodiesterase III inhibitor used in patients with intermittent claudication, which has been shown to reduce complaints and increase walking distance. It causes vasodilation in the vein, inhibition of platelet activation and aggregation, inhibition of thrombosis, and inhibition of smooth muscle proliferation. It also increases blood flow to the extremities (14). The effectiveness of cilostazol on maximum walking distance, ankle-brachial index (ABI), quality of life and functional status of patients with intermediate-advanced stage intermittent claudication (IC) due to PAH has been shown in many studies (15).

In this study, the effectiveness of lumbar sympathectomy and cilostosol treatment will be encountered in PAH that can not be revascularized due to critical leg ischemia.

\section{MATERIAL AND METHOD}

This retrospective study was conducted between january 2017 and august 2020 in Kirıkkale University, Faculty of Medicine, Department of Cardiovascular Surgery. All phases of the study were conducted in accordance with human participants, national research committee standards and ethical guidelines regarding the 1964 Helsinki Declaration and its subsequent editions. This study was approved by Kirıkkale University Faculty of Medicine, Non-interventional Research Ethics Committee (Date: 30.09.2020, Decision No: 2020.09.11).

\section{Study Plan and Patient Selection Criteria}

Patients who underwent lumbar sympathectomy and cilostazol treatment in PAH that could not be revascularized and had critical leg ischemia were identified from the hospital registry system and their files were examined. The demographic characteristics of the patients, diagnoses, comorbidity, arterial color doppler ultrasonography (USG) report, computed tomography angio report, accompanying diseases, walking distance, ischemic pain scale, wound healing and complications were determined and evaluated from the records.

Patients with obstructing lesions in the popliteal artery and its distal and not suitable for surgery and percutaneous angioplasty were included in the study. Critical foot ischemia patients who required primary amputation and presented with functionally unrecoverable limbs were excluded from the study. Class 3-4 patients with critical foot ischemia, ischemic rest pain or foot wounds were included in the study according to the Fontaine classification. A total of 30 patients who were eligible after screening participated in the study. While 15 of them were in the patient group who underwent lumbar sympathectomy (Group 1), 15 of them made up the group receiving cilostazol (Group 2). There were 2 patients with resting pain in Group 1 and 3 patients in Group 2. Five patients with ischemic lower extremity wounds were identified in both groups.

The ischemic pain of the patients included in the study was evaluated using the visual analog scale (VAS) before treatment and at the $3^{\text {rd }}, 6^{\text {th }}, 12^{\text {th }}$ and $24^{\text {th }}$ months. Patients were asked to score their current pain between 1-10 when they walked 150 meters. 0 points were classified as no pain, 1-2 points mild pain, 3-4 points slightly more pain, 5-6 points moderate pain, 7 and above points severe pain and 10 points the most severe pain. The average of the scores obtained for the patients was taken $(16,17)$.

Each patient who could be on the treadmill was taken to the treadmill for the $3^{\text {rd }}, 6^{\text {th }}, 12^{\text {th }}$ and $24^{\text {th }}$ months before the treatment and the patients were asked to walk at a speed of $0.3 \mathrm{~km} / \mathrm{h}$ until the unbearable pain appeared and their walking distance was recorded. 2 patients with severe resting pain in group 1 and 3 patients in group 2 were not included in the walking test.

The ischemic wounds of the hospitalized patients were evaluated before treatment, at the $3^{\text {rd }}, 6^{\text {th }}, 12^{\text {th }}$ and $24^{\text {th }}$ months. Wound culture was taken from those who had open wounds on hospitalization and daily wound care was applied. Morphine was administered as a $1 \mathrm{mg}$ bolus to patients with severe resting pain. Afterwards, an infusion of $0.3 \mathrm{mg} / \mathrm{h}$ was started by connecting PCA (patient control analgesia). Acetylsalicylic acid $100 \mathrm{mg}$ was started in all patients as an antiaggregant. Morphine treatment was terminated on the $2^{\text {nd }}$ day and paracetamol $500 \mathrm{mg}$ was started to be administered three times a day. In this way, the pains were taken under control. Cilostazol treatment was administered to the patients orally $2 \times 100 \mathrm{mg} /$ day for 24 months. All patients were treated for cardiovascular risks. Absolute smoking cessation, lipid-lowering therapy, hypertension and diabetes were brought under control.

Patients undergoing sympathectomy were operated on after bowel cleansing the day before the surgery. The operation was performed under general anesthesia and by reaching the retroperitoneal area with a paramedian incision. During the performance of the procedure, attention was paid to all kinds of dissection on the vena cava, and bleeding that could occur due to the thin and easily detached lumbar branches was avoided. First, the upper part of the sympathetic chain was palpated along the spine and dissected as far as possible to the crest of 
the diaphragm. In order to expand the boundaries of the sympathectomy, the chain was pulled parallel to the length of the chain to prevent rupture and bleeding in any vessel by separating the chain from neighboring tissues. The most important anatomical feature at this point is to know that the genitofemoral nerve runs over the psoas muscle and that the sympathetic chain follows a course close to the periosteum of the vertebrae. In the procedure, attention was paid to the removal of the bilateral lumbar $2^{\text {nd }}, 3^{\text {rd }}$ and $4^{\text {th }}$ ganglia. The removed sympathetic chain was sent for pathological examination.

\section{Statistical Analysis}

SPSS (Statistical Package for Social Sciences) for Windows 21.0 (SPSS Inc, Chicago, IL) program was used for statistical analysis of the findings obtained in the study. Shapiro Wilk test was used to examine the distributions of the variables. Continuous quantitative data; $\mathrm{n}$ is expressed as mean and standard deviation, qualitative data are expressed as $n$ and ratio (\%).The t-Test was used for within-group comparisons. ANNOVA test was used for comparisons between groups. The results were evaluated at a $95 \%$ confidence interval, and the significance level was $\mathrm{p}<0.05$.

\section{RESULTS}

A total of 30 patients followed for 24 months were included in the study. 7 of the patients were female and 23 of them were male. The average age of Group 1 was 51.73, and the average age of Group 2 was 53.81. In the etiology of the patients, 23 had buerger (thromboangitis obliterans) and 7 had arteriosclerosis obliterans. There was no statistically significant difference between the demographic data, patient diagnoses and comorbidity data of the groups $(\mathrm{p}>0.05)$. The data are shown in Table 1.

When the pre-treatment, $3^{\text {rd }}, 6^{\text {th }}, 12^{\text {th }}$, and $24^{\text {th }}$ month walking distance data of Group 1 and Group 2 were compared, no statistically significant difference was found ( $p>0.05)$. The data are shown in Table 2 .

\begin{tabular}{|c|c|c|c|}
\hline \multirow{2}{*}{$\begin{array}{l}\text { Walking } \\
\text { distance (meter) }\end{array}$} & Group $1(n=15)$ & Group $2(n=15)$ & \multirow{2}{*}{$\mathbf{p}$} \\
\hline & mean \pm std & mean \pm std & \\
\hline Pre-treatment & $114.00 \pm 85.34$ & $106.00 \pm 84.41$ & 0.718 \\
\hline $3^{\text {rd }}$ month & $122.12 \pm 88.45$ & $112.93 \pm 86.53$ & 0.699 \\
\hline $6^{\text {th }}$ month & $132.67 \pm 86.64$ & $145.33 \pm 82.36$ & 0.685 \\
\hline $12^{\text {th }}$ month & $155.67 \pm 95.11$ & $190.00 \pm 91.03$ & 0.321 \\
\hline $24^{\text {th }}$ month & $189.33 \pm 102.91$ & $237.33 \pm 108.52$ & 0.224 \\
\hline
\end{tabular}

When the pre-treatment, $3^{\text {rd }}, 6^{\text {th }}, 12^{\text {th }}$, and $24^{\text {th }}$ month ischemic pain data of Group 1 and Group 2 were compared, no statistically significant difference was found $(\mathrm{p}>0.05)$. The data are shown in Table 3.

\begin{tabular}{|lccc|}
\hline \multicolumn{3}{|l}{ Table 3. Analysis of ischemic pain between groups } & \\
\cline { 1 - 3 } $\begin{array}{l}\text { Visual analog scale } \\
\text { (VAS) 0 to 10 score }\end{array}$ & Group 1 $(\mathbf{n}=\mathbf{1 5})$ & Group 2 $(\mathbf{n}=\mathbf{1 5})$ & \\
\cline { 2 - 3 } Pre-treatment & $6.40 \pm 1.45$ & $6.46 \pm 1.85$ & 0.913 \\
$3^{\text {rd }}$ month & $6.16 \pm 1.52$ & $5.99 \pm 1.78$ & 0.468 \\
$6^{\text {th }}$ month & $5.40 \pm 1.30$ & $5.06 \pm 1.66$ & 0.546 \\
$12^{\text {th }}$ month & $4.66 \pm 1.18$ & $4.20 \pm 1.42$ & 0.336 \\
$24^{\text {th }}$ month & $3.60 \pm 1.35$ & $3.2 \pm 1.26$ & 0.410 \\
\hline std: standard deviation & & & \\
\hline
\end{tabular}

In the intergroup comparisons in Group 1 and Group 2, a statistically significant difference was found between the walking distance data before treatment and the walking distance data at the $3^{\text {rd }}, 6^{\text {th }}, 12^{\text {th }}$ and $24^{\text {th }}$ months $(p<0.001)$. The data are shown in Table 4 .

\begin{tabular}{|lcccc|}
\hline Table 4. In-group walking distance analysis \\
\hline $\begin{array}{l}\text { Walking } \\
\text { distance (meter) }\end{array}$ & $\begin{array}{c}\text { Group 1 }(\mathbf{n}=\mathbf{1 5}) \\
\text { mean } \pm \text { std }\end{array}$ & $\mathbf{p}^{*}$ & \multicolumn{2}{c|}{ Group 2 $(\mathbf{n}=\mathbf{1 5})$} \\
mean \pm std & $\mathbf{p}^{*}$ \\
\hline Pre-treatment & $114.00 \pm 85.34$ & & $106.00 \pm 84.41$ & \\
$3^{\text {rd }}$ month & $122.12 \pm 88.45$ & $<0.001$ & $112.93 \pm 86.53$ & $<0.001$ \\
$6^{\text {th }}$ month & $132.67 \pm 86.64$ & $<0.001$ & $145.33 \pm 82.36$ & $<0.001$ \\
$12^{\text {th }}$ month & $155.67 \pm 95.11$ & $<0.001$ & $190.00 \pm 91.03$ & $<0.001$ \\
$24^{\text {th }}$ month & $189.33 \pm 102.91$ & $<0.001$ & $237.33 \pm 108.52$ & $<0.001$ \\
\hline $\mathrm{P}^{*}$ value calculated based on pre-treatment data. ss: standard deviation. \\
\hline \multicolumn{5}{|l}{} \\
\hline
\end{tabular}

\begin{tabular}{|c|c|c|c|c|c|c|c|c|}
\hline & & \multicolumn{3}{|c|}{ Group $1(n=15)$} & \multicolumn{3}{|c|}{ Group $2(n=15)$} & \multirow{2}{*}{$\mathbf{p}$} \\
\hline & & $\mathbf{n}$ & $\%$ & mean \pm std & n & $\%$ & mean \pm std & \\
\hline Age (yea & & & & $51.73 \pm 3.1$ & & & $53.81 \pm 4.7$ & $>0.05$ \\
\hline \multirow{2}{*}{ Gender } & Female & 4 & 26.66 & & 3 & 20 & & $>0.05$ \\
\hline & Male & 11 & 73.33 & & 12 & 80 & & $>0.05$ \\
\hline \multicolumn{2}{|c|}{ Smoking } & 11 & 73.33 & & 9 & 60 & & $>0.05$ \\
\hline \multicolumn{2}{|c|}{ Buerger (Thromboangitis Obliterans) } & 12 & 80 & & 11 & 73.33 & & $>0.05$ \\
\hline \multicolumn{2}{|c|}{ Arteriosclerosis obliterans } & 3 & 20 & & 4 & 26.66 & & $>0.05$ \\
\hline \multicolumn{2}{|c|}{$\mathrm{DM}$} & 5 & 33.33 & & 4 & 26.66 & & $>0.05$ \\
\hline \multicolumn{2}{|l|}{ HT } & 3 & 20 & & 4 & 26.66 & & $>0.05$ \\
\hline \multicolumn{2}{|l|}{$\mathrm{DL}$} & 1 & 6.63 & & 3 & 20 & & $>0.05$ \\
\hline \multicolumn{2}{|l|}{ CAD } & 2 & 13.33 & & 3 & 20 & & $>0.05$ \\
\hline
\end{tabular}


In group 1 and Group 2 comparisons, a statistically significant difference was found between the ischemic pain data before treatment and the ischemic pain data at the $3^{\text {rd }}, 6^{\text {th }}, 12^{\text {th }}$ and $24^{\text {th }}$ months $(\mathrm{p}<0.001)$. The data are shown in Table 5 .

\begin{tabular}{|l|cccc|}
\hline Table 5. In-group ischemic pain analysis \\
\hline $\begin{array}{l}\text { Visual analog scale } \\
\text { (VAS) 0 to 10 score }\end{array}$ & \multicolumn{2}{c|}{ Group 1 $(\mathbf{n}=\mathbf{1 5})$} & \multicolumn{3}{c|}{ Group 2 } & (n=15) \\
\cline { 2 - 5 } & mean \pm std & $\mathbf{p}^{*}$ & mean \pm std & $\mathbf{p}^{*}$ \\
\hline Pre-treatment & $6.40 \pm 1.45$ & & $6.46 \pm 1.85$ & \\
$3^{\text {rd }}$ month & $6.16 \pm 1.52$ & $<0.001$ & $5.99 \pm 1.78$ & $<0.001$ \\
$6^{\text {th }}$ month & $5.40 \pm 1.30$ & $<0.001$ & $5.06 \pm 1.66$ & $<0.001$ \\
$12^{\text {th }}$ month & $4.66 \pm 1.18$ & $<0.001$ & $4.20 \pm 1.42$ & $<0.001$ \\
$24^{\text {th }}$ month & $3.60 \pm 1.35$ & $<0.001$ & $3.2 \pm 1.26$ & $<0.001$ \\
\hline $\mathrm{P}^{*}$ value calculated based on pre-treatment data. ss: standard deviation. \\
\hline
\end{tabular}

While 3 of 5 patients with ischemic wound ulcers in Group 1 had complete wound healing in their 6th month follow-up, the other two had ischemic wounds recovered at $12^{\text {th }}$ month follow-up. There was no wound in the $24^{\text {th }}$ month controls. In Group 2, the wounds of 4 of 5 patients with ischemic wound ulcer healed at the 6th month controls and one patient's ischemic wound healed at the $12^{\text {th }}$ month controls. There was no patient who developed wounds at the $24^{\text {th }}$ month controls.

No postoperative complications (surgical bleeding, incision infection, retrograde ejaculation, post sympathectomy neuralgia, retroperitoneal abscess) were observed. No patient discontinued cilostazol treatment

\section{DISCUSSION}

In recent studies, it has been observed that medical treatment is preferred more in the treatment of $\mathrm{PAH}$, in which lumbar sympathectomy decreases (18). However, there is no study in the literature showing the superiority of cilostazol over lumbar sympathectomy (19). In addition, there are studies reporting that the use of prostonids used in the later stages of critical leg ischemia is restricted due to patient compliance and side effects. It has been stated that sympathectomy may be superior to medical treatment in terms of patient compliance and cost, and more studies are required on this subject (20). In addition, in our country, it is still found as a condition in which sympathectomy should be applied for treatment in the social security incapacity scale for buerger patients (21).

Today, medical treatment is started as the first step in peripheral artery diseases, and combinations of exercise, statin, antiplatelet, anticoagulant and vasodilator drugs are used in the medical treatment (22). In the diabetic patient group, strict blood glucose monitoring is additionally recommended. Medical treatment, which is included in the treatment algorithm at the beginning of the treatment algorithm in most patient groups, is highly useful in chronic asymptomatic patients, while it is generally insufficient in patients with critical leg ischemia. For this, first of all, surgical revascularization or percutaneous procedures should be intervened. Since many patient groups have distal bed disease, revascularization cannot be performed and the disease manifests itself in the form of claudication intermittent, resting pain and ischemic wounds. This can seriously impair the comfort of life of the patients and can lead to limb amputation (23).

In the treatment of critical leg ischemia that cannot be revascularized for many years, lumbar sympathectomy applied following the cessation of smoking in many patients has been proven to have an effective role in saving the foot and leg $(24,25)$. In our study, we determined that it increased the preopertaif walking distance from $114 \mathrm{~m}$ on average to 189.33 meters at the end of the $24^{\text {th }}$ month, and reduced the ischemic pain scale average from 6.4 to 3.6 at the end of the $24^{\text {th }}$ month. Both results are statistically significant $(\mathrm{p}<0.05)$. In addition, in 5 patients with ischemic wound ulcers, it was found that the ischemic wounds were completely closed at the end of the $12^{\text {th }}$ month and no wound was formed again in the $24^{\text {th }}$ month. These results show that lumbar sympathectomy is an effective treatment modality in patients with critical leg ischemia.

Cilostazol, a phosphodiesterase III inhibitor, is known to significantly improve walking distances in patients with stable, moderate to severe intermittent claudication $(26,27)$. Cilostazol, which is used as an effective treatment option for symptomatic improvement and increasing walking distance in peripheral artery patients with intermittent claudication, has also been observed in our study. While the average walking distance of cilostazol before treatment was $106 \mathrm{~m}$, it reached 213.33 meters at the end of the $24^{\text {th }}$ month, while the average pain scale before treatment was 6.46 in the ischemic pain scale, while the average ischemic pain scale decreased to 3.22 in the $24^{\text {th }}$ month control after treatment. Both results were found to be statistically significant $(\mathrm{p}<0.05)$. In 5 patients with ischemic wounds, the wounds were closed after 12 months at the beginning of the treatment, and no recurrence was observed at the $24^{\text {th }}$ month controls. We think that regular follow-up and treatment of the patients may have been effective in this.

When we compare both groups with each other in our study; There was no statistically significant difference between the sympathectomy group and the ciloztazol group at the pre-treatment, $3^{\text {rd }}, 6^{\text {th }}, 12^{\text {th }}$ and $24^{\text {th }}$ month follow-up ( $p>0.05$ ). As a result, it was seen that although both treatment methods are effective treatment methods, there is no significant difference on each other. Especially the increase in walking distance and decrease in ischemic pain on the $24^{\text {th }}$ month stand out as the time period in which the treatment efficiency reaches the highest level. 
Peripheral artery diseases with critical leg ischemia are more common in the patient group accompanied by many diseases such as atherosclerotic heart disease, carotid artery disease, heart failure, and uncontrolled diabetes (28). Although the lumbar sympathectomy procedure applied in group 1 is a simple, safe and low mortality operation, the surgical procedure and its associated complications, general anesthesia risks and hospitalization can be seen as a disadvantage. Surgical complications include surgical bleeding, incision infection, retrograde ejaculation, post sympathectomy neuralgia, and retroperitoneal abscess (28). In our study, no complications were encountered in patients who underwent lumbar sympathectomy. In addition, no patient discontinued cilostazol treatment.

The first limiting factor is that this study was conducted in a retrospective, single center, and small patient group. The second limiting factor is the inability to differentiate Burger's disease and atherosclerosis obliterans. Again, not being able to differentiate between diabetic and nondiabetic is seen as the third limiting factor. We think that studies with larger patient groups will achieve results that support this study.

\section{CONCLUSION}

In line with these results obtained from the study, although both lumbar sympathectomy and cilostosol therapy were shown as effective treatment methods in $\mathrm{PAH}$ with critical leg ischemia, no significant difference was found between each other. Especially in the 24th month, the increase in walking distance and the decrease in ischemic pain stand out as the time period in which the treatment efficiency reaches the highest level. Cilostazol treatment stands out as a good alternative to sympathectomy in the treatment of $\mathrm{PAH}$, which is critical leg ischemia that cannot be revascularized, considering the surgical risks.

\section{ETHICAL DECLARATIONS}

Ethics Committee Approval: This study was approved by Kırıkkale University Faculty of Medicine, NonInterventional Researchs Ethics Committee (Date: 30.09.2020, Decision No: 2020.09.11).

Informed Consent: Because the study was designed retrospectively, no written informed consent form was obtained from patients.

Referee Evaluation Process: Externally peer-reviewed.

Conflict of Interest Statement: The authors have no conflicts of interest to declare.

Financial Disclosure: The authors declared that this study has received no financial support.
Author Contributions: All of the authors declare that they have all participated in the design, execution, and analysis of the paper, and that they have approved the final version.

\section{REFERENCES}

1. Lange S, Diehm C, Darius H, et al. High prevalence of peripheral arterial disease but low antiplatelet treatment rates in elderly primary care patients with diabetes. Diabetes Care 2003; 26: 33578 .

2. Welten GM, Schouten O, Hoeks SE, et al. Long-term prognosis of patients with peripheral arterial disease: a comparison in patients with coronary artery disease. J Am Coll Cardiol 2008; 5: 1588-96.

3. Meijer WT, Hoes AW, Rutgers D, Bots ML, Hofman A, Grobbee DE. Peripheral arterial disease in the elderly: The Rotterdam Study. Arterioscler Thromb Vasc Biol 1998; 18: 185-92.

4. Tokgözoğlu L, Bariş Kaya E. Atherosclerotic vascular disease and risk factors in Turkey: from past to present. J Atheroscler Thromb 2008; 15: 286-91.

5. McDermott MM, Greenland P, Liu K, et al. The ankle brachial index is associated with leg function and physical activity: the Walking and Leg Circulation Study. Ann Intern Med 2002; 136: 873-83.

6. Yao ST, Hobbs JT, Irvine WT. Ankle systolic pressure measurements in arterial disease affecting the lower extremities. Br J Surg 1969; 56: 676-9.

7. Gardner AW, Afaq A. Management of lower extremity peripheral arterial disease. J Cardiopulm Rehabil Prev 2008; 28: 349-57.

8. Dormandy J, Heeck L, Vig S. The natural history of claudication: risk to life and limb. Semin Vasc Surg 1999; 12: 123-37.

9. Akay H, Ersöz A, Yavuzer Ş. Lomber sempatektomi yapılan 322 vakada postoperatif gangren komplikasyonu. Mavi Bülten 1978; 10: 227-38.

10.Blumenberg MR, Gelfant M. Sempatectomy for limp salvage Agoal line stand Am J Surg 1979; 138: 241-5.

11. Cross FW. Lumbar sympathectomy. Cardiovasc Surg 1997; 7: 1514.

12.Bozer AY, Günay 1. Damar Hastalıkları ve Cerrahisi. 1st ed. Ankara, Hacettepe Üniversitesi Yayınları, 1984.

13.Solak H. Göğüs Kalp ve Damar Hastalıkları Cerrahisi. 1st ed. Konya, Atlas Kitabevi, 1992.

14. Weintraub WS. The vascular effects of cilostazol. Can J Cardiol 2006; 22: 56-60.

15. Crouse JR, Allan MC, Elam MB. Clinical manifestation of atherosclerotic peripheral arterial disease and the role of cilostazol in treatment of intermittent claudication. J Clin Pharma col 2002; 42:1291-8.

16. Hawker GA, Mian S, Kendzerska T, French M. Measures of adult pain. Arthritis Care Res 2011; 63: 240-52

17. Bijur PE, Silwer W, Gallagher EJ. Reliability of the visual analog scale for measurement of acute pain. Acad Emerg Med 2001; 8: 1153-7.

18. Cacione DG, Moreno DH, Nakano LC, Baptista-Silva JC. Surgical sympathectomy for Buerger's disease. JRSM Open 2017; 8: 1-8.

19. Pekař M, Mazur M, Pekařová A, Kozák J, Foltys A. Lumbar sympathectomy literature review over the past 15 years. Rozhl Chir 2016; 95: 101-6.

20.Sen I, Agarwal S, Tharyan P, Forster R. Lumbar sympathectomy versus prostanoids for critical limb ischaemia due to nonreconstructable peripheral arterial disease. Cochrane Database Syst Rev 2018; 4: 1-22.

21.SGK. Özür Oranları Cetveli, Resmi Gazete 20.02.2019/30692, https://www.resmigazete.gov.tr/eskiler/2019/02/ 20190220-2.htm 
22. Berkan Ö, Saba T, Önen A, Uçarı H, Doğan K. Sempatektomi sonuçlarının değerlendirilmesi. Türk Göğüs Kalp Damar Cerrahisi Derg 1999; 7: 263-5.

23. Tenna AS, Alex Watson A, Stansby G. Revascularization for critical limb ischemia in diabetes: surgery or angioplasty? Angiology 2014; 65: 272-3

24. Lau H, Cheng SW. Buerger's disease in Hong Kong: a review of 89 cases. Aust N Z J Surg 1997; 67: 264-9.

25.Dawson DL, Cutler BS, Meissner MH, Strandness DE. Cilostazol has beneficial effects in treatment of intermittent claudication: Results from a multicenter, randomized, prospective, doubleblind trial. Circulation 1998; 98: 678-86.

26. Desai K, Han B, Laila Kuziez L, Yan Y, Zayed MA. Literature review and meta-analysis of the efficacy of cilostazol on limb salvage rates after infrainguinal endovascular and open revascularization. Vasc Surg. 2021; 73: 711-21.

27. Mya MM, Aronow WS. Increased prevalence of peripheral arterial disease in older men and women with subclinical hypothyroidism. J Gerontol A Biol Sci Med Sci 2003; 58: 68-9.

28. Matarazzo A, Rosati TV, Sassi O, Florio O, Tatafiore M. Possibilities at present for the application of lumbar sympathectomy in occlusive arterial disease of the lower limbs. Minerva Cardioangiol 2002; 50: 363-9. 